\title{
OCCURRENCE OF PENTA-AROMATIC HYDROCARBONS IN JAINTIAAND BARAIL GROUP MUDSTONES, NORTHEASTERN BENGAL BASIN, BANGLADESH
}

\author{
H. M. Zakir Hossain ${ }^{1}$, Md. Sultan-Ul-Islam², Quazi Hasna Hossain ${ }^{3}$ \\ ${ }^{1}$ Department of Petroleum and Mining Engineering, Jessore University of Science and Technology, \\ Jessore-7408, Bangladesh \\ ${ }^{2}$ Department of Geology and Mining, University of Rajshahi, Rajshahi-6205, Bangladesh \\ ${ }^{3}$ Department of Geoscience, Shimane University, 1060 Nishikawatsu, Matsue 690-8504, Japan \\ *Corresponding author; E-mail: zakirgsd@yahoo.com (H.M.Z. Hossain)
}

\begin{abstract}
In the present experiment, concentration, distribution and sources of penta-aromatic hydrocarbons in seven drill core and outcrop samples from Jaintia and Barail Group mudstones, northeastern Bengal Basin, Bangladesh have been studied. Gas chromatography-mass spectrometry (GC-MS) was used to obtain composition details about the sedimentary organic matter (OM). Mudstone samples were found to contain relatively high penta-aromatic hydrocarbon abundances in the lower Jaintia Group than in the overlying Barail Group. High concentration of perylene suggests terrigenous sources and significantly higher content of total organic carbon in the samples. A biogenic origin of perylene therefore indicates oxygen deficient environmental condition for deposition of OM. Perylene over pentacyclic aromatic hydrocarbon isomers regulating in-situ diagenetic origin.
\end{abstract}

Key words: Mudstone, penta-aromatic hydrocarbons, GC-MS, Bengal Basin, Bangladesh

সারাংশ: বর্তমান গবেষণায় উত্তরপূর্ব বেঙ্গল বেসিনের জয়ন্তিয়া এবং বরাইল গ্রপেপর কর্দম শিলার পেন্টা-অ্যারোম্যাটিক হাইড্রোকার্বন বৈশিষ্ট্য নিয়ে আলোচনা করা হয়। গবেষণায় দেখা যায় যে, বরাইল গ্রপপের কর্দম শিলার চাইতে জয়ন্তিয়া কর্দম শিলায় পেন্টা-অ্যারোম্যাটিক হাইড্রোকার্বনের পরিমাণ বেশি। এসব পললে বিদ্যমান বেশি পরিমাণ পেরিলিন মহাদেশীয় উৎস অঞ্চল এবং অপেক্ষাকৃত কম অক্সিজেন সম্পন্ন পরিবেশের ইংগিত প্রদান করে। তবে পেন্টাসাইক্লিক অ্যারোম্যাটিক হাইদ্রোকার্বন আইসোমারের তুলনায় বেশি পরিমাণ পেরিলিন অবক্ষেপণ পরবর্তী স্থানীয় পরিবর্তন নির্দেশ করে।

\section{Introduction}

Polycyclic aromatic hydrocarbons (PAHs) in sediments and sedimentary rocks have been studied by many authors (Aizenshtat, 1973; Wakeham et al., 1979, 1980; Jiang et al., 1998, 2000; Grimalt et al., 2004; Grice et al., 2007; Hossain et al., 2013a). PAHs are widely distributed in soils (Youngblood and Blumer, 1975; Blumer and Youngblood, 1975), lake sediments (Laflamme and Hites, 1978; Giger and Schaffner, 1978; Wakeham et al., 1980; Gschwend and Hites, 1981; Kawamura et al., 1987), recent marine sediments (Aizenshtat, 1973; Youngblood and Blumer, 1975; Hites et al., 1977; Wakeham et al., 1979; Gschwend and Hites, 1981), river particulates as well as estuary sediments (Giger and Schaffner, 1978; Hites et al., 1980; Brown and Maher, 1992), and peats or coals (Aizenshtat, 1973; Venkatesan, 1988; Garrigues et al., 1988; Hossain et al., 2013b).

Penta-aromatic hydrocarbons especially benzo $[b, j, k]$ fluoranthene (Bflas), benzo [e] pyrene (BePy) and benzo $[a]$ pyrene (BaPy) are common in recent and ancient sediments (Baumard et al., 1998; Jiang et al., 1998, 2000; Readman et al., 2002; Bakhtiari et al., 2009). This hydrocarbon has been originated from biological precursors through diagenesis in continental and marine OM (Aizenshtat, 1973; Laflamme and Hites, 1978; Hites et al., 1980; Tan and Heit, 1981; Tan et al., 1996; Jiang et al., 1998; Grice et al., 2009). Perylene is a penta-aromatic hydrocarbon being derived from aquatic and continental organic matter in anoxic environments (Aizenshtat, 1973; Wakeham et al., 1979; Silliman et al., 2000; Suzuki et al., 2010).

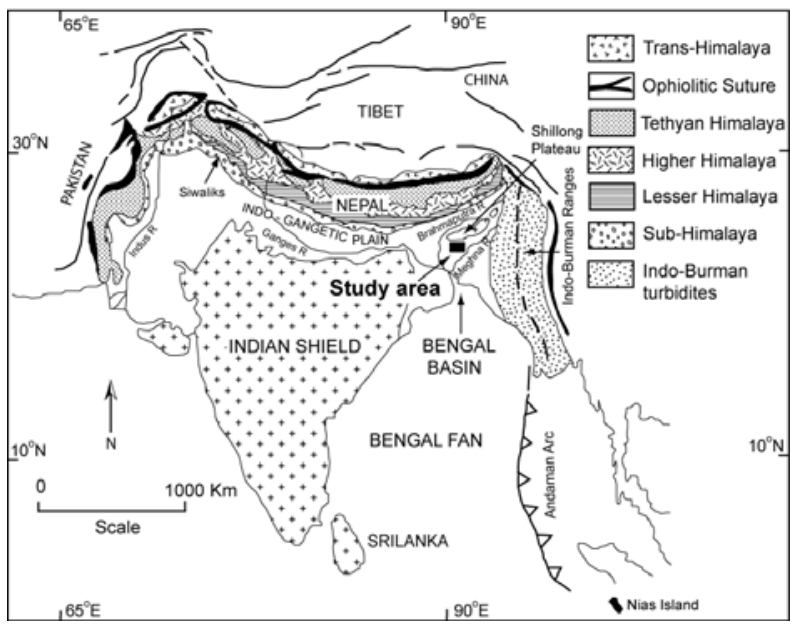

Fig. 1 Geological map showing location of the sample sites and major geographic features of the Himalayas (after Hossain et al., 2010).

The Bengal Basin is placed between the Indian Shield Platform and the Indo-Burman Ranges. It is bounded to the north by Shillong Plateau and plunges into the Bay 
of Bengal to the south (Fig. 1). The Sylhet basin is located immediately after the Shillong Plateau (Fig. 1). This basin is an elongated trough consists mainly of alternating bed of sandstone and mudstone (Alam et al., 2003). The present study groups in the Sylhet succession are mainly Jaintia and Barail which is located in the lower part of Sylhet succession, northeastern Bengal Basin, Bangladesh (Fig. 2). Biomarker studies of the Bengal Basin mudstones are very few (Alam and Pearson, 1993; Hossain et al., 2009a, b, 2013a). The aim of this study was to recognize distribution and sources of penta-aromatic hydrocarbons in Jaintia and Barail Group mudstones, northeastern Bengal Basin, Bangladesh.

\section{Geological setting}

The Bengal Basin was formed during the collision between India, Eurasia and Myanmar (former Burma), beginning at about $45 \mathrm{Ma}$ (Gansser, 1964) building the Himalayan orogen and Indo-Burman ranges (Uddin and Lundberg, 1998). Based on the results of geophysical investigations, geological mapping, and on well data, Reimann (1993) classified the principal structural elements of the Bengal Basin and of the adjacent areas into a number of environments. These are the Fold Belt, Bengal Foredeep, Continental Slope, Western Foreland Shelf, Dauki Fault Zone, Rangpur Saddle, and the Himalayan Foredeep. The sediment fill of the Bengal Basin comprises about $22 \mathrm{~km}$ of Paleocene to Holocene deposits (Alam et al., 2003). The Basin is bounded to the east and west by Indo-Burman ranges and West Bengal. North is bounded by Shillong Plateau and to the south it plunges into the Bay of Bengal (Fig. 1). The Bengal delta, world's largest delta, has been formed through the seaward prograding deltas of the Ganges, Brahmaputra and Meghna rivers system (Einsele et al., 1996; Alam et al., 2003).

The Sylhet basin, a sub-basin in the northeastern Bengal Basin, consists of a thick Tertiary sedimentary succession, comprising sandstones, shales, fossiliferous limestones, deposited on the passive continental margin. Sediments of the Sylhet basin were derived from Himalayan detritus (Hossain et al., 2010). Alam et al. (2003) reported the Sylhet basin is tectonically placed in the central deep part of the Bengal Basin. The Sylhet basin is situated in the Bengal Foredeep of the Bengal Basin (Reimann, 1993). Aeromagnetic interpretation map suggests gradual deepening of the basement towards the center of the basin, and also shows the presence of subsurface synclinal features and faults within the basin (Mannan, 2002). The syncline was a major depocentre for accumulation of late Neogene and Holocene deposits. Anticlinal structures within the Sylhet basin include the Atgram, Sylhet, Chattak, Kailas Tila, Beani Bazar, Patharia, Fenchuganj, Rasidpur and Habiganj anticlines (Fig. 2). The Tertiary Sylhet succession comprises into several groups including Jaintia, Barail, Surma, Tipam and Dupitila and their constituent formations in ascending order of Paleocene to Plio-Pleistocene in age Table 1. In this paper we examined only the lower part of the Sylhet succession including Paleocene to late Eocene Jaintia and late Eocene to early Miocene Barail Groups respectively (Hossain et al., 2010).

The Jaintia Group is the lowermost unit of the Tertiary stratigraphic succession in the Sylhet basin. Rocks of the Group are mainly fossiliferous and calcareous in nature, and are divided into three distinct and prominent formations, the Tura Sandstone, Sylhet Limestone and the Kopili Shale Formations, in ascending order. These units were deposited during repeated transgressive and regressive phases during the Paleocene to Eocene period.

The Tura Sandstone Formation consists mostly of quartz arenites with some carbonaceous materials and impure limestones, and was deposited in shallow to deep marine environments (Khan, 1991; Uddin and Lundberg, 1999; Najman et al., 2008). The Sylhet Limestone Formation, which conformably overlies the Tura Sandstone Formation, consists mainly of nummulitic limestone interbedded with minor sandstone (Reimann, 1993). It is interpreted as a shallow-marine carbonate deposit (Shamsuddin and Abdullah, 1997). The overlying Kopili Shale Formation consists mainly of argillaceous and fossiliferous materials, interbedded with sandstones and occasional thin limestones. Presence of fossiliferous sediments in the formation indicates distal deltaic to shelf or slope depositional environments (Alam et al., 2003).

The Barail Group was deposited during the Oligocene period, when basin-wide emergence and a major marine regression occurred (Alam et al., 2003). It is divided into the Jenam and Renji Formations. The Jenam Formation consisting mainly of siltstones, silty shales, and sandstones with minor carbonaceous shales (Khan, 1978). The Renji Formation, consisting mostly of fine grained sandstones, alternating with siltstones, and calcareous and carbonaceous shales with a few coal lenses (Reimann, 1993). The contact between the Renji Formation and the overlying Surma Group is marked by a distinct unconformity. Barail Group sediments have been deposited in shallow-marine and deltaic environments (Banerji, 1981; Johnson and Alam, 1991). Alam (1991) reported that the Barail Group sediments were deposited in tide-dominated shelf environments. 


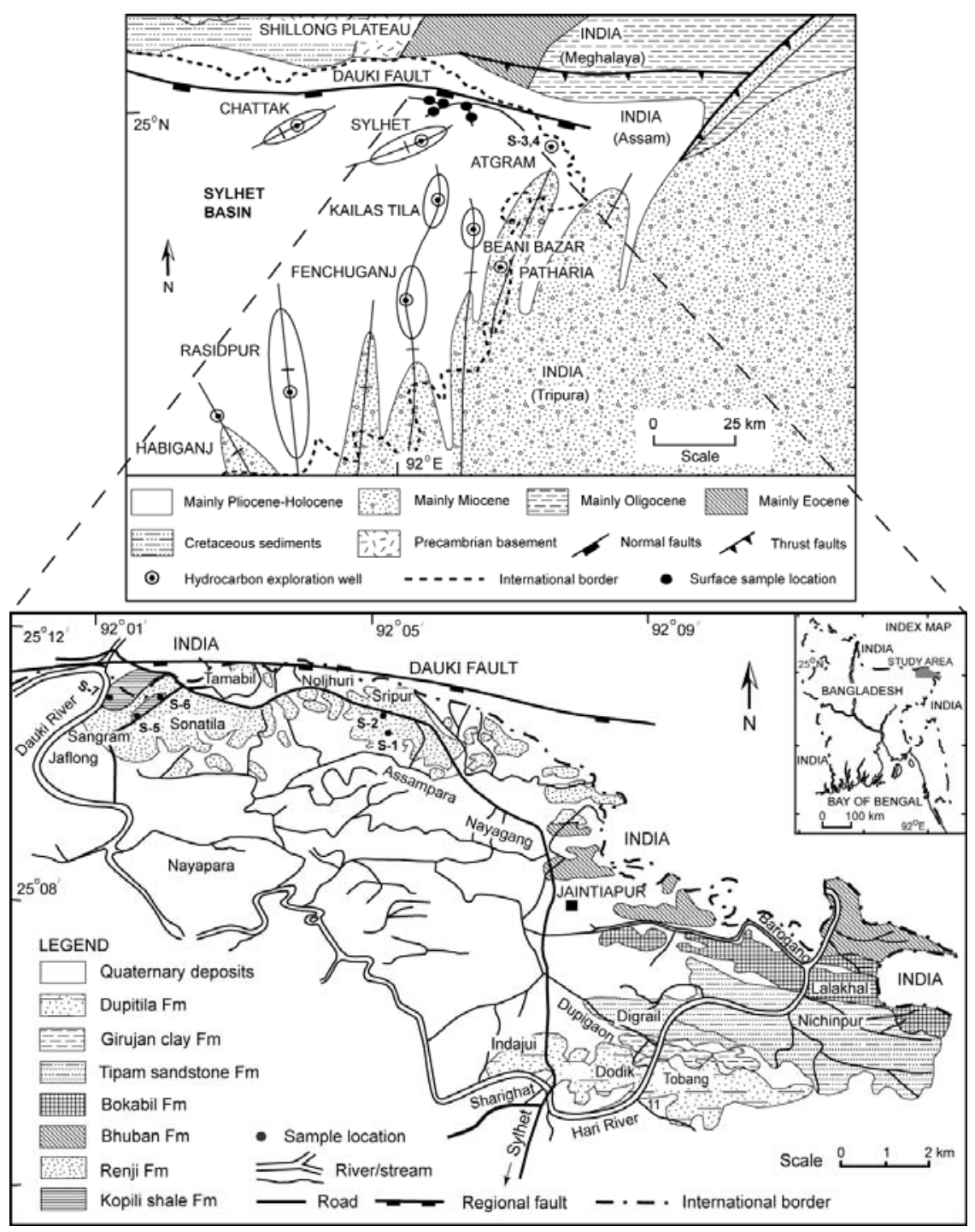

Fig. 2 (a) Map showing location of the study area and hydrocarbon exploration wells in the Sylhet basin, Bangladesh (after Hossain et al., 2009a, 2013a), (b) geological map showing lithotypes and surface sample points in the study area (after Hossain et al., 2009a). Cores were taken from Atgram-1X well.

\section{Materials and Methods}

\section{Sample collection and preparation}

Indurated mudstone samples were collected from Jaintia and Barail Group, Sylhet basin, Bangladesh. The sections were located between latitude $25^{\circ} 04^{\prime} \mathrm{N}$ to $25^{\circ} 12^{\prime} 30^{\prime \prime} \mathrm{N}$ and longitude $92^{\circ} 01^{\prime} \mathrm{E}$ to $92^{\circ} 12^{\prime} 30^{\prime \prime} \mathrm{E}$. Locations of the sample points are indicated in Fig. 2. Rock samples were manually disaggregated or chipped, and then rinsed in deionized distilled water and dried at $110{ }^{\circ} \mathrm{C}$ prior to crushing. The oven-dried samples were then crushed in a tungsten-carbide ring mill, with mills times generally between 30 to 45 seconds.

\section{Solvent extraction and separation}

Powdered mudstone sample ( $\sim 40 \mathrm{gm}$ ) was used to extract hydrocarbon solvent in a Soxhlet apparatus for 72 hours using a mixture of dichloromethane and methanol (9:1). Cupper granules were used to separate elemental sulfur. Hydrocarbon solvent was separated using a rotary evaporator. Aromatic hydrocarbon was then separated using thin layer chromatography on activated silica gel (Kiselgel 60 PF254, Merk) eluting with $n$-hexane.

\section{Gas chromatography-mass spectrometry (GC-MS)}

The aromatic hydrocarbon fractions were performed using gas chromatography-mass spectrometry (GC-MS) 
with a Shimadzu QP2010 instrument at Shimane University, Japan. The chromatograph was equipped with an automatic temperature programmable injection system and a fused silica capillary column coated with chemical bound (DB-5MS of $30 \mathrm{~m} \times 0.25 \mathrm{~mm}$ i.d.). The interface temperature was held at 50 to $300^{\circ} \mathrm{C}$. The oven temperature program was used at heating rate $8{ }^{\circ} \mathrm{C}$ $\min ^{-1}$. Helium was used as a carrier gas with flow rates of $1.69 \mathrm{ml} \mathrm{min}^{-1}$. GC-MS analyses were performed initially on a Finnigan MAT TSQ-700 system using electron impact potential ionization of $70 \mathrm{eV}$ with a mass range 50 to $850 \mathrm{~m} / \mathrm{z}$ and a cycle time of 0.5 seconds. The total ion chromatograms (TICs) of the GC-MS were identified based on their mass spectra and retention times (Killops and Massoud, 1992; Jiang et al., 1998, 2000; Grice et al., 2007).

Table 1 Stratigraphy of the Sylhet succession, northeastern Bengal Basin, Bangladesh (after Hossain et al., 2010).

\begin{tabular}{|c|c|c|c|c|}
\hline Age & Group & Formation & Lithology & Depositional Environments \\
\hline Recent & Alluvium & Alluvium & Sand, silt, clay & Fluvial \\
\hline Late Pleistocene & Dihing & Dihing & Sandstone, shale & Fluvial $^{\text {a }}$ \\
\hline Pliocene-Pleistocene & Dupi Tila & Dupi Tila & Sandstone, shale & Fluvial b,f \\
\hline \multirow{2}{*}{ Late Miocene-Pliocene } & \multirow{2}{*}{ Tipam } & Girujan Clay & Clay, sandstone & Fluvial $^{\mathrm{c}}$, lacustrine ${ }^{\mathrm{c}}$ \\
\hline & & Tipam Sandstone & Sandstone, shale & Fluvial $b, f$ \\
\hline \multirow{2}{*}{ Middle-Late Miocene } & \multirow{2}{*}{ Surma } & Boka Bil & Sandstone, shale & \multirow{2}{*}{ Marine ${ }^{c, d}$, deltaic b,c,f } \\
\hline & & Bhuban & Sandstone, shale & \\
\hline \multirow{2}{*}{$\begin{array}{l}\text { Late Eocene-Early } \\
\text { Miocene }\end{array}$} & \multirow{2}{*}{ Barail } & Renji & Sandstone, shale & \multirow{2}{*}{ Shallow marine ${ }^{\mathrm{c}}$, deltaic ${ }^{\mathrm{f}}$} \\
\hline & & Jenam & Shale, sandstone & \\
\hline Late Eocene & \multirow{3}{*}{ Jaintia } & Kopili Shale & Shale, minor lst. & Shallow marine ${ }^{\mathrm{c}}$, deltaic $\mathrm{e}^{\mathrm{e}}$ \\
\hline Early-Middle Eocene & & Sylhet Limestone & Limestone & Shallow marine $e^{c, d}$ \\
\hline Paleocene-Early Eocene & & Tura Sandstone & Quartz arenites & Shallow marine ${ }^{a, b, f}$ \\
\hline
\end{tabular}

\section{Results}

The measured Penta-aromatic hydrocarbons and their respective concentration (percentage) in individual sample are shown in Table 2. Distribution of Pentaaromatic hydrocarbons is illustrated in Fig. 3. The Jaintia Group mudstone samples contained relatively high concentration of benzo[b,j,k]fluoranthene than overlying Barail Group samples. In the Renji Formation, benzo[b,j,k]fluoranthene is almost constant ( 10\%). Similarly, abundances of benzo[e]pyrene are similar in the underlying Jenam Formation mudstones (Table 2). Concentration of perylene was abundant in the Jaintia Group samples (up to 37.07 \%) than overlying Barail Group samples with high total organic carbon (TOC) content (Hossain et al., 2009a). In the Barail Group, perylene concentration was relatively abundant in the upper part (32.42 to 25.91\%) than in the lower part (10.99 to $15.92 \%)$. A number of samples contained relatively low perylene content (Table 2). Higher molecular weight PAHs were identified in the top layer of each group than in the bottom layer sample. Abundances of benzo $[b, j, k]$ fluoranthene, benzo [e]pyrene and benzo [a] pyrene are relatively high in sample of the lower Jaintia Group (Table 2). Samples in the lower Jaintia Group contain relatively low perylene content (12.69\%). Abundance of benzo[e]pyrene and perylene in the upper Jaintia Group samples are mostly uniform (about $18.21 \%$ and $37.07 \%$ respectively).

\section{Discussion}

The PAHs, benzo[b,j,k]fluoranthene, benzo[e]pyrene and benzo[a]pyrene may be originated from combustion products (Jiang et al., 1998). The distribution of combustion-derived PAHs may be modified by subsequent sedimentary alkylation procedures (Alexander et al., 1995; Smith et al., 1995; Jiang et al., 1998). Benzo[e]pyrene is the most stable PAHs among the Bflas, BaPy and perylene (Sullivan et al., 1989). Therefore, benzo[e]pyrene may be the least susceptible to post-depositional modifications (Jiang et al., 1998). Combustion derived PAHs take place from combustion of vegetation. Benzo[e]pyrene most probably derived from forest fires as well as peat fires (Jiang et al., 1998). High relative abundance of 
Table 2 Concentrations (\%) of benzo[b,j,k]fluoranthene, benzo[e]pyrene, benzo[a]pyrene and perylene in Jaintia and Barail Group mudstones, northeastern Bengal Basin, Bangladesh (Hossain et al., 2013a). Abbreviation: PAI, Pentacyclic aromatic isomers (Bflas, BePy, BaPy) and TOC, total organic carbon.

\begin{tabular}{|c|c|c|c|c|c|c|c|c|c|c|}
\hline Sample & Group & Formation & $\begin{array}{c}\text { Bflas } \\
m / z \quad 252\end{array}$ & $\begin{array}{c}\text { ВеPy } \\
m / z 252\end{array}$ & $\begin{array}{c}\text { BaPy } \\
m / z \quad 252\end{array}$ & $\begin{array}{c}\text { Pery } \\
m / z 252\end{array}$ & PAI & $\begin{array}{l}\text { TOC* } \\
\text { (wt\%) }\end{array}$ & ВaPy/BePy & Bflas/(Bflas+BePy) \\
\hline S-1 & Barail & Renji & 10.16 & 45.02 & 18.90 & 25.91 & 74.09 & 1.56 & 0.42 & 0.18 \\
\hline S-2 & Barail & Renji & 10.68 & 34.48 & 22.43 & 32.42 & 67.58 & 1.19 & 0.65 & 0.24 \\
\hline S-3 & Barail & Jenam & 14.81 & 53.58 & 20.62 & 10.99 & 89.01 & 0.60 & 0.38 & 0.22 \\
\hline S-4 & Barail & Jenam & 22.10 & 53.00 & 8.99 & 15.92 & 84.08 & 0.80 & 0.17 & 0.29 \\
\hline S-5 & Jaintia & Kopili Shale & 23.47 & 18.21 & 21.25 & 37.07 & 62.93 & 1.20 & 1.17 & 0.56 \\
\hline S-6 & Jaintia & Kopili Shale & 26.54 & 18.22 & 18.17 & 37.07 & 62.93 & 0.90 & 1.00 & 0.59 \\
\hline S-7 & Jaintia & Kopili Shale & 31.59 & 36.73 & 19.00 & 12.69 & 87.31 & 1.18 & 0.52 & 0.46 \\
\hline
\end{tabular}

*: cited from Hossain et al. (2009a)

Benzo[e]pyrene in the Jenam and lower Jaintia samples suggested that their derivation from combustion of forest or peat materials.

Perylene concentration increases during depth of burial of OM (Grimalt et al., 2004; Grice et al., 2009). In the Jaintia Group, abundances of perylene are uniform towards upper part, where as low values in the bottom part samples. Concentration of perylene is relatively lower in the overlying Barail Group mudstones (Table 2). The high values therefore suggest in-situ biogenic sources. Perylene is abundant in marine, lake and river sediments either aquatic or terrigenous in anoxic environments (Hites et al., 1980; Silliman et al., 1998; Jiang et al., 2000; Grimalt et al., 2004). Perylene could also originate from fungi (e.g., wood-degrading fungi) within anoxic marine environment (Grice et al., 2009; Nabbefeld et al., 2010). Sediments in the Sylhet succession were accumulated in deltaic to marine environmental conditions (Reimann, 1993). OM of the Jaintia and Barail Groups was deposited mainly in marine dominated oxic conditions, with abundant inputs of terrestrial higher plant material (Hossain et al., 2009a). Therefore, influx of perylene in the Jaintia and Barail Group mudstones probably linked with deltaic OM sources subsequently deposited in oxic-anoxic environmental conditions.

Abundances of perylene relative to pentacyclic aromatic isomers (PAI, summed values of Bflas, BePy, $\mathrm{BaPy}$ ) are important for derivation of combustion or diagenetic sources (Hites et al., 1980; Venkatesan, 1988; Baumard et al., 1998; Readman et al., 2002; Bakhtiari et al., 2009; Fan et al., 2011). Perylene abundance $>10 \%$ relative to PAI representing diagenetic sources (Hites et al., 1980; Venkatesan, 1988 ) and $<10 \%$ representing combustion sources (Baumard et al., 1998; Readman et al., 2002; Bakhtiari et al., 2009). Abundance of perylene to PAI in the
Jaintia and Barail Group mudstones ranging from 10\% to over $20 \%$ suggesting both diagenetic and combustion sources.

Elevated level of perylene concentration in sediments is occasionally favored by the control of TOC (Agbozu and Opuene, 2009; Bakhtiari et al., 2009; Fan et al., 2011). In the Barail Group, perylene versus TOC concentrations show a marked positive correlation $(r=0.80)$ and clear linear trend (Fig. 4), inferring that concentrations of perylene in the Barail Group mudstones may be dependent on the abundances of TOC. Conversely, correlation between perylene versus TOC concentrations in the Jaintia Group shows no correlation, suggesting that TOC does not influence the concentration of perylene in these mudstones. Perylene in the Jaintia Group most likely derived from different sources. Fan et al. (2011) reported that high influx of perylene in mudstones probably originated from erosion of soils/sedimentary rocks under strong influence of steady state environmental condition. This is consistent with the study of Hossain et al. (2010) and concluded that Paleocene to late Eocene Jaintia Group mudstones contained relatively high chemical index of alteration (CIA) values (up to 85) subsequently originated from a stable cratonic source.

The ratios of BaPy/BePy and Bflas/(Bflas + BePy) is used to identify source of PAHs. The values of $\mathrm{BaPy} / \mathrm{BePy}$ in the Jaintia and Barail Group mudstones ranging from 0.52 to 0.1 .17 and 0.17 to 0.65 , respectively (Table 2), inferring that combustion and petrogenic sources throughout the sequence (Khalili et al. 1995). The ratio values of Bflas/(Bflas + BePy) are less than 0.20 indicate petroleum combustion, between 0.20 and 0.50 indicate fossil fuel combustion, and values greater than 0.50 are characteristics of grass, wood and coal combustion (Shengli et al., 2010). In the late Eocene Jaintia Group, Bflas/ (Bflas + BePy) ratios 


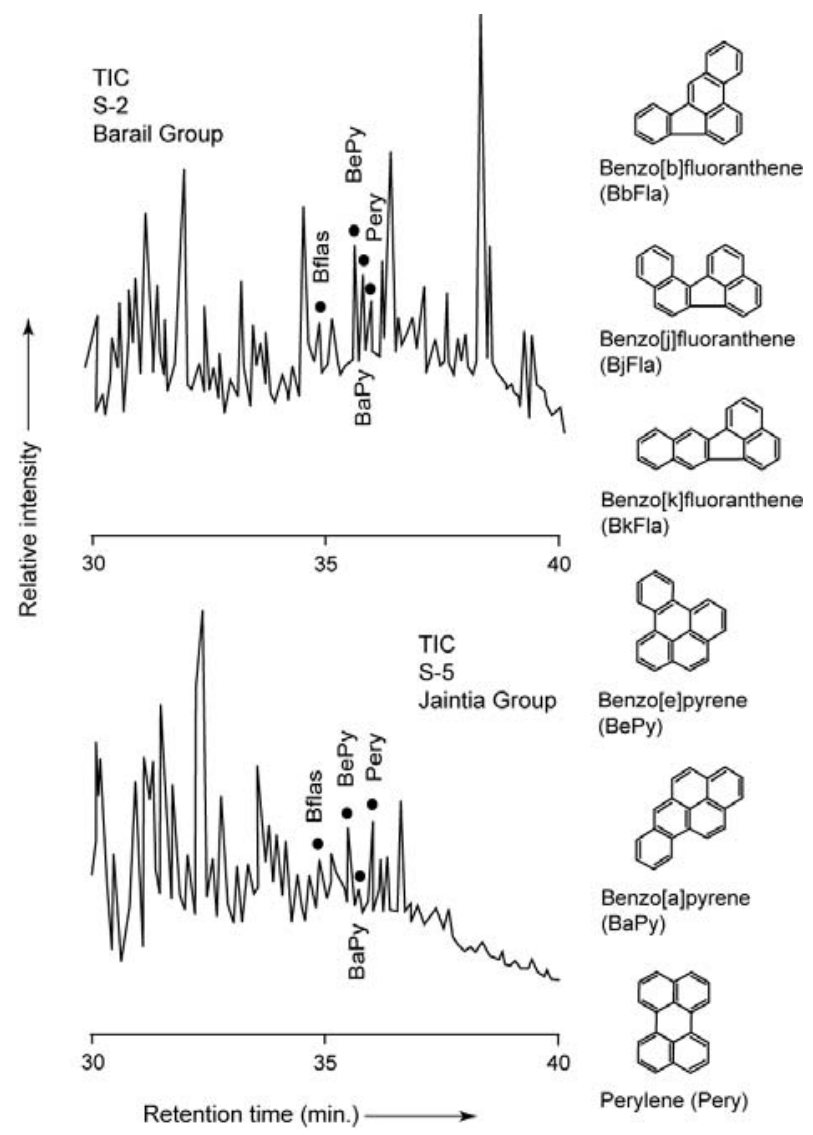

Fig. 3 Representative total ion chromatograms (TICs) showing distributions of benzo[b,j,k]fluoranthene $(\mathrm{m} / \mathrm{z} \quad 252)$, benzo[e]pyrene $(\mathrm{m} / \mathrm{z} 252)$, benzo[a]pyrene $(\mathrm{m} / \mathrm{z} 252)$ and perylene $(\mathrm{m} / \mathrm{z}$ 252) in the Jaintia and Barail Group mudstones, northeastern Bengal Basin, Bangladesh.

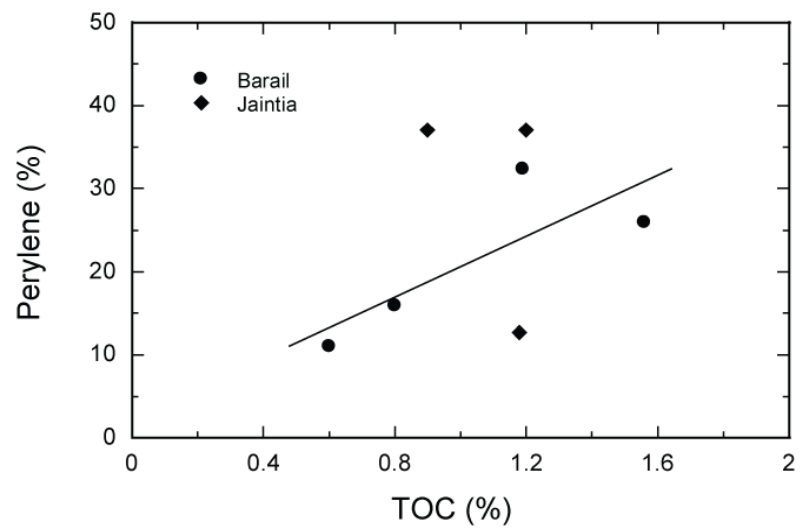

Fig. 4 Variation diagram between TOC (\%) and perylene (\%) in the Jaintia and Barail Group mudstones, northeastern Bengal Basin, Bangladesh. TOC data from Hossain et al. (2009a).

range from 0.46 to 0.59 suggesting combustion of grass, wood and coal. The overlying Jenam and Renji formations in the late Eocene to middle Miocene Barail Group, ratios of Bflas/(Bflas + BePy) range from 0.22 to 0.29 and 0.18 to 0.24 , respectively suggested that PAHs in the group were derived from combustion sources.

\section{Conclusions}

Penta-aromatic hydrocarbons in the Jaintia and Barail Group mudstones, northeastern Bengal Basin, Bangladesh have been studied. Distributions of Bflas, BePy and perylene were abundant in Barail Group than underlying Jaintia Group. High concentration of perylene in the Barail Group mudstones suggesting diagenetic influences subsequently derived from terrigenous organic matter sources. Abundances of perylene increase with increasing depth of the succession inferring that influx of perylene may deposited under oxic/anoxic environmental condition. Combustion sources of PAI were also identified as evidences by high Bflas/(Bflas + BePy) ratio values in the studied mudstones.

Acknowledgements: The authors would like to thank Bangladesh Petroleum Exploration and Production Company (BAPEX) and Bangladesh Oil, Gas and Mineral Corporation (PETROBANGLA) for provided samples and well log data. We also thank M.K. Roy, I. Hossain and A.K.M.M. Kabir for assistance during sample collection and Prof. Y. Sampei for access to the GC-MS facilities. We are grateful to Prof. Nishit Kumar Paul, Executive Editor and two anonymous reviewers for their valuable comments and suggestions to an earlier version of the manuscript.

\section{References}

Agbozu IE and Opuene K. 2009. Occurrence and diagenetic evolution of perylene in the sediments of Oginigba Creek, Southern Nigeria. International Journal Environmental Research 3: 117-120.

Aizenshtat Z. 1973. Perylene and its geochemical significance. Geochimica et Cosmochimica Acta 37: 559-567.

Alam M and Pearson MJ. 1993. Bicadinanes and other terrestrial terpenoids in immature Oligocene sedimentary rocks and a related oil from the Surma Basin, NE Bangladesh. Organic Geochemistry 20: 539-554.

Alam M, Alam MM, Curray JR, Chowdhury MLR and Gani MR. 2003. An overview of the sedimentary geology of the Bengal Basin in relation to the regional tectonic framework and basinfill history. Sedimentary Geology 155: 179-208.

Alexander R, Bastow TP, Fisher S and Kagi RI. 1995. Geosynthesis of organic compounds: II. Methylation of phenanthrene and alkylphenanthrenes. Geochimica et Cosmochimica Acta 59: 4259-4266. 
Bakhtiari AR, Zakaria MP, Yaziz MI, Lajis MNH, Bi X and Rahim MCA. 2009. Vertical distribution and source identification of polycyclic aromatic hydrocarbons in anoxic sediment cores of Chini Lake, Malaysia: Perylene as indicator of land plantderived hydrocarbons. Applied Geochemistry 24: 1777-1787.

Banerji RK. 1981. Cretaceous-Eocene sedimentation, tectonism and biofacies in the Bengal basin, India. Palaeogeography, Palaeoclimatology, Palaeoecology 34: 57-85.

Baumard P, Budzinski H and Garrigues P. 1998. Polycyclic aromatic hydrocarbons in sediments and mussels of the western Mediterranean Sea. Environmental Toxicology and Chemistry 17: 765-776.

Blumer M and Youngblood WW. 1975. Polycyclic aromatic hydrocarbons in soils and recent sediments. Science 188: 53-55.

Brown G and Maher W. 1992. The occurrence, distribution and sources of polycyclic aromatic hydrocarbons in the sediments of the George River Estuary, Australia. Organic Geochemistry 18: 657-668.

Einsele G, Ratschbacher L and Wetzel A. 1996. The HimalayaBengal Fan denudation-accumulation system during the past 20 Ma. Journal of Geology 104: 163-184.

Fan C-W, Shiue J, Wu C-Y and Wu C-Y. 2011. Perylene dominance in sediments from a subtropical high mountain lake. Organic Geochemistry 42: 116-119.

Gansser A. 1964. Geology of the Himalayas. Interscience, London, p. 289.

Garrigues P, De Sury R, Angelin ML, Bellocq J, Oudin JL and Ewald M. 1988. Relation of the methylated aromatic hydrocarbon distribution pattern to the maturity of organic matter in ancient sediments from the Mahakam delta. Geochimica et Cosmochimica Acta 52: 375-384.

Giger W and Schaffner C. 1978. Determination of polycyclic aromatic hydrocarbons in the environment by glass capillary gas chromatography. Analytical Chemistry 50: 243-249.

Grice K, Lu H, Atahan P, Asif M, Hallmann C, Greenwood P, Maslen E, Tulipani S, Williford K and Dodson J. 2009. New insights into the origin of perylene in geological samples. Geochimica et Cosmochimica Acta 73: 6531-6543.

Grice K, Nabbefeld B and Maslen E. 2007. Source and significance of selected polycyclic aromatic hydrocarbons in sediments (Hovea-3 well, Perth Basin, Western Australia) spanning the PermianTriassic boundary. Organic Geochemistry 38: 1795-1803.

Grimalt JO, Drooge BLV, Ribes A, Fernández P and Appleby P. 2004. Polycyclic aromatic hydrocarbon composition in soils and sediments of high altitude lakes. Environmental Pollution 131: 13-24.

Gschwend PM and Hites RA. 1981. Fluxes of polycyclic aromatic hydrocarbons to marine and lacustrine sediments in the northeastern United States. Geochimica et Cosmochimica Acta 45: 2359-2367.

Hiller K and Elahi M. 1984. Structural development and hydrocarbon entrapment in the Surma Basin, Bangladesh (northwest IndoBurman fold belt). Fifth Offshore South East Asia Conference, Singapore, p. 650-663

Hites RA, Laflamme RE and Farrington JW. 1977. Sedimentary polycyclic aromatic hydrocarbons: the historical records. Science 198: 829-831.

Hites RA, Laflamme RE, Windsor Jr JG, Farrington JW and Werner GD. 1980. Polycyclic aromatic hydrocarbons in an anoxic sediment core from the Pettaquamscutt River (Rhode Island, USA). Geochimica et Cosmochimica Acta 44: 873-878.
Hossain HMZ, Sampei Y, Hossain QH, Roser BP and Islam MS. 2013b. Characterization of alkyl phenanthrene distributions in Permian Gondwana coals and coaly shales from the Barapukuria Basin, NW Bangladesh. Researches in Organic Geochemistry 29: 17-28.

Hossain HMZ, Sampei Y and Roser BP. 2013a. Polycyclic aromatic hydrocarbons (PAHs) in late Eocene to early Pleistocene mudstones of the Sylhet succession, NE Bengal Basin, Bangladesh: Implications for source and paleoclimate conditions during Himalayan uplift. Organic Geochemistry 56: 25-39.

Hossain HMZ, Roser BP and Kimura J-I. 2010. Petrography and whole-rock geochemistry of the Tertiary Sylhet succession, northeastern Bengal Basin, Bangladesh: Provenance and source area weathering. Sedimentary Geology 228: 171-183.

Hossain HMZ, Sampei Y and Roser BP. 2009a. Characterization of organic matter and depositional environment of Tertiary mudstones from the Sylhet Basin, Bangladesh. Organic Geochemistry 40: 743-754.

Hossain HMZ, Sampei Y and Roser BP. 2009b. Influence of organic matter type on the distribution of tri-aromatic hydrocarbons in Tertiary mudstones in the Sylhet Basin, Bangladesh. Researches in Organic Geochemistry 25: 39-52.

Jiang C, Alexander R, Kagi RI and Murray AP. 1998. Polycyclic aromatic hydrocarbons in ancient sediments and their relationships to palaeoclimate. Organic Geochemistry 29: $1721-1735$.

Jiang C, Alexander R, Kagi RI and Murray AP. 2000. Origin of perylene in ancient sediments and its geological significance. Organic Geochemistry 31: 1545-1559.

Johnson SY and Alam AMN. 1991. Sedimentation and tectonics of the Sylhet trough, Bangladesh. Geological Society of America Bulletin 103: 1513-1527.

Kawamura K, Ogura K and Ishiwatari R. 1987. Early diagenesis of organic matter in the water column and sediments: microbial degradation and resynthesis of lipids in Lake Haruna. Organic Geochemistry 11: 251-264.

Khalili NR, Scheff PA and Holsen TM. 1995. PAH source fingerprints for coke ovens, diesel and gasoline engines, highway tunnels, and wood combustion emissions. Atmospheric Environment 29: 533-542.

Khan FH. 1991. Geology of Bangladesh. The University Press Limited, Dhaka, pp. 207.

Khan MAM. 1978.Geology of the eastern and the north-eastern part of sadar sub-division, Sylhet district, Bangladesh. Geological Survey of Bangladesh. Records 2: 1-19.

Killops SD and Massoud MS. 1992. Polycyclic aromatic hydrocarbons of pyrolytic origin in ancient sediments: evidence for Jurassic vegetation fires. Organic Geochemistry 18: 1-7.

Laflamme RE and Hites RA. 1978. The global distribution of polycyclic aromatic hydrocarbons in recent sediments. Geochimica et Cosmochimica Acta 42: 289-303.

Mannan A. 2002. Stratigraphic evolution and geochemistry of the Neogene Surma Group, Surma Basin, Sylhet, Bangladesh. Published Doctoral thesis. Institute of Geosciences and Astronomy, Department of Geology, University of Oulu, Finland, $190 \mathrm{p}$.

Nabbefeld B, Grice K, Summons RE, Hays LE and Cao C. 2010. Significance of polycyclic aromatic hydrocarbons (PAHs) in Permian/Triassic boundary sections. Applied Geochemistry 25: 1374-1382. 
Najman Y, Bickle M, BouDagher-Fadel M, Carter A, Garzanti E, Paul M, Wijbrans J, Willett E, Oliver G, Parrish R, Akhter SH, Allen R, Ando S, Chisty E, Reisberg L and Vezzoli G. 2008. The Paleogene record of Himalayan erosion: Bengal Basin, Bangladesh. Earth and Planetary Science Letters 273: 1-14.

Readman JW, Fillmann G, Tolosa I, Bartocci J, Villeneuve P, Catinni $\mathrm{C}$ and Mee LD. 2002. Petroleum and PAH contamination of Black Sea. Marine Pollution Bulletin 44: 48-62.

Reimann K-U. 1993. Geology of Bangladesh. Gebrüder Borntraeger, Berlin, pp. 160.

Shamsuddin AHM and Abdullah SKM. 1997. Geologic evolution of the Bengal Basin and its implication in hydrocarbon exploration in Bangladesh. Indian Journal of Geology 69: 93-121.

Shengli Z, Rencheng L, Shucheng X, Junying Z, Xinjun W and Junhua H. 2010. Paleofire indicated by polycyclic aromatic hydrocarbons in soil of Jinluojia archaeological site, Hubei, China. Journal of Earth Science 21: 247-256.

Silliman JE, Meyers PA and Eadie BJ. 1998. Perylene: an indicator of alteration processes or precursor materials? Organic Geochemistry 29: 1737-1744.

Silliman JE, Meyers PA, Ostrom PH, Ostrom NE and Eadie BJ. 2000. Insights into the origin of perylene from isotopic analyses of sediments from Saanich Inlet, British Columbia. Organic Geochemistry 31: 1133-1142.

Smith JW, George SC and Batts BD. 1995. The geosynthesis of alkylaromatics. Organic Geochemistry 23: 71-80.

Sullivan RF, Boduszynski MM and Fetzer JC. 1989. Molecular transformations in hydrotreating and hydrocracking. Energy and Fuels 3: 603-612.

Suzuki N, Yessalina S and Kikuchi T. 2010. Probable fungal origin of perylene in Late Cretaceous to Paleogene terrestrial sedimentary rocks of northeastern Japan as indicated from stable carbon isotopes. Organic Geochemistry 41: 234-241.
Tan YL and Heit M. 1981. Biogenic and abiogenic polynuclear aromatic hydrocarbons in sediments from two remote Adirondack lakes. Geochimica et Cosmochimica Acta 45: 2267-2279.

Tan YL, Kong A and Monetti M. 1996. Biogenic polycyclic aromatic hydrocarbons in an Alaskan arctic lake sediment. Polycyclic Aromatic Compounds 9: 185-192.

Uddin A and Lundberg N. 1998. Cenozoic history of the HimalayanBengal system: sand composition in the Bengal basin, Bangladesh. Geological Society of America Bulletin 110: 497-511.

Uddin A and Lundberg N. 1999. A paleo-Brahmaputra? Subsurface lithofacies analysis of Miocene deltaic sediments in the Himalayan-Bengal system, Bangladesh. Sedimentary Geology 123: 239-254.

Venkatesan MI. 1988. Occurrence and possible sources of perylene in marine sediments - a review. Marine Chemistry 25: 1-27.

Wakeham S, Schaffner C and Giger G. 1980. Polycyclic aromatic hydrocarbons in recent lake sediments: II. Compounds derived from biogenic precursors during early diagenesis. Geochimica et Cosmochimica Acta 44: 415-429.

Wakeham SG, Schaffner C, Giger W, Boon JJ and Leeuw JWD. 1979. Perylene in sediments from the Namibian Shelf. Geochimica et Cosmochimica Acta 43: 1141-1144.

Youngblood WW and Blumer M. 1975. Polycyclic aromatic hydrocarbons in the environment: homologous series in soils and recent sediments. Geochimica et Cosmochimica Acta 39: $1303-1314$.

Manuscript received on 1 December 2013 and revised on 21 December 2013 